\title{
IGUALDADE DE GÊNERO NA CONSTITUIÇÃO FEDERAL DE 1988: 0 MOVIMENTO FEMINISTA BRASILEIRO E A CONSQUISTA DO PRINCÍPIO DA IGUALDADE
}

\author{
Bibiana Terra* \\ Bianca Tito** $^{* *}$
}

\begin{abstract}
RESUMO: Considerando-se a trajetória de luta das mulheres brasileiras, muitas vezes por intermédio do movimento feminista, essa pesquisa tem como objetivo analisar a conquista do Princípio da Igualdade na Constituição Federal de 1988. O seu inciso I do artigo $5^{\circ}$ prevê que homens e mulheres são iguais em direitos e obrigações, sendo este um marco da igualdade de gênero no Brasil. Para a sua realização foi adotada a metodologia da pesquisa bibliográfica e traz como resultados que a Constituição Federal de 1988 foi explícita ao declarar a igualdade entre homens e mulheres, sendo que essa previsão resulta de demandas feministas.
\end{abstract}

Palavras-chave: Feminismo; Princípio da Igualdade; Direito das Mulheres; Constituição Federal de 1988; Igualdade de gênero.

\section{GENDER EQUALITY IN THE 1988 FEDERAL CONSTITUTION: THE BRAZILIAN FEMINIST MOVEMENT AND THE ACHIEVEMENT OF THE PRINCIPLE OF EQUALITY}

\begin{abstract}
Considering the trajectory of brazilian women's struggle, often through the feminist movement, this research aims to analyze the achievement of the Principle of Equality in the 1988 Federal Constitution. Its item I of article 5 provides that men and women are equal in rights and obligations, which is a milestone of gender equality in Brazil. For its realization, the bibliographic research methodology was adopted and it brings as results that the Federal Constitution of 1988 was explicit in declaring equality between men and women, and this prediction was part of feminist demands.
\end{abstract}

Key-words: Feminism; Principle of Equality; Women's Rights; Federal Constitution of 1988; Gender Equality.

\footnotetext{
* Mestra em Direito, com ênfase em Constitucionalismo e Democracia, na Linha de Pesquisa Relações Sociais e Democracia, pela Faculdade de Direito do Sul de Minas (FDSM). Especialista em Direito Constitucional pela Universidade Anhanguera-Uniderp. Graduada em Direito pela Pontifícia Universidade Católica de Minas Gerais - PUC Minas. Advogada e pesquisadora. E-mail: bibianaterra@yahoo.com

** Mestra em Direito, com ênfase em Constitucionalismo e Democracia, pela Faculdade de Direito do Sul de Minas - FDSM. Especialista em Direito de Família e das Sucessões pela Universidade Anhanguera-Uniderp. Graduada em Direto pela Pontifícia Universidade Católica de Minas Gerais - PUC Minas. Advogada (OAB/MG) e pesquisadora. E-mail: biancaberaldo tito@outlook.com
} 


\section{Introdução}

Os movimentos sociais feministas foram um importante marco durante as décadas passadas, tendo exercido influências na reformulação constitucional e na redemocratização do país (PITANGUY, 2019, p. 81-96). Nesse sentido, a luta por direitos iguais entre homens e mulheres fortaleceu-se, tornando necessária a prática, não apenas formal, mas efetiva do texto constitucional, no que diz respeito, principalmente, à efetiva concretização e cumprimento dos direitos a igualdade e dignidade humana.

É diante desse cenário que essa pesquisa se insere. Considerando-se a trajetória de luta das mulheres brasileiras, muitas vezes por intermédio do movimento feminista, o presente artigo tem como objetivo central analisar a sua influência na conquista do inciso I, do artigo $5^{\circ}$, do texto constitucional de 1988 , que prevê que homens e mulheres são iguais em direitos e obrigações. Nesse sentido, busca refletir acerca da conquista desse Princípio e da atuação das feministas durante o processo constituinte de 1987 e 1988, que culminou na promulgação da vigente Constituição Federal.

Para tanto, destaca-se que o trabalho seguirá um ordenamento cronológico-histórico, em que abordará as lutas do movimento feminista brasileiro e o papel das mulheres na influência da edição do Princípio da Igualdade e na sua atuação no processo constituinte. A Constituição Federal de 1988 abriu possibilidades para a construção de um novo patamar de evolução dos direitos dos cidadãos brasileiros, trazendo, dentre suas conquistas, a consagração do Princípio da Igualdade no inciso I do artigo $5^{\circ}$. É considerada, por isso, uma das legislações mais avançadas em termos de direitos e cidadania, sendo que este Princípio é elementar para a garantia da democracia e para a construção dos valores sociais (CANOTILHO; MENDES; SARLET; STRECK, 2013).

Sendo assim, essa pesquisa sinaliza uma importante conquista na luta do movimento feminista e dos direitos das mulheres brasileiras, que foi a previsão do Princípio da Igualdade no texto constitucional de 1988. No contexto brasileiro, com a abertura democrática dos anos 1980 as questões das mulheres passaram a ganhar mais espaço no campo jurídico, em um período marcado pela efervescência de lutas sociais que perpassavam por diferentes temas e pela busca por reformas constitucionais, participação política e transformações institucionais (PITANGUY, 2019, p. 81-96). 
A sua realização justifica-se pela importância que é inerente aos estudos que versem quanto a temática da igualdade de gênero, bem como pela necessidade de trabalhos que discutam este direito frente as questões específicas que lhe são concernentes. Assim, a relevância do tema é notável, considerando-se essa trajetória de lutas das mulheres até os dias atuais na busca para conquistar o status de sujeito de direitos, estabelecer a sua igualdade em relação aos homens, bem como para garantir leis relativas à emancipação do gênero feminino.

Para tanto, é utilizada como metodologia a realização de pesquisa de natureza exploratória, por meio de adoção do método bibliográfico, vez que este diz respeito à parte dedicada à contextualização teórica do problema e a sua relação com o que já tem sido investigado a seu respeito. Utilizando como base materiais elaborados, constituídos principalmente por livros e artigos científicos que versam quanto à temática da igualdade de gênero, o seu referencial teórico será construído majoritariamente a partir de textos e obras de teóricas feministas brasileiras. Essa escolha se justifica na medida em que o tema central do trabalho é gênero, sendo que as autoras que serão utilizadas possuem produções específicas sobre a temática a ser desenvolvida.

Para essa análise, nos estreitos limites desse trabalho, será inicialmente apresentada uma breve análise histórica do movimento feminista no Brasil. A seguir, a pesquisa abordará acerca da Assembleia Nacional Constituinte de 1987 e 1988, destacando a atuação do Conselho Nacional dos Direitos da Mulher e as reivindicações feministas. Por fim, apresentará uma abordagem sobre a conquista do Princípio da Igualdade na Constituição Federal promulgada em 1988.

É importante destacar que a Constituição Federal de 1988 abriu espaço para a construção de um novo patamar de evolução dos direitos dos cidadãos, trazendo, dentre suas conquistas, a consagração da igualdade de gênero entre homens e mulheres. Nesse sentido, importa ressaltar que foi com a abertura democrática nos anos 1980 que as questões dos direitos das mulheres e outras relacionadas a gênero passaram a, de fato, ganhar espaço de reivindicação no campo jurídico.

\section{O movimento feminista no Brasil: Uma breve análise histórica}

A busca por igualdade de gênero e pelo reconhecimento dos direitos das mulheres fez emergir no Brasil, influenciado pelos ideais iluministas, o movimento feminista. Assim, esse 
trata-se de um longo movimento social e histórico do qual as mulheres surgem como sujeitos políticos, questionando o seu lugar de subordinadas ao homem e a falta de reconhecimento de seus direitos. Diversos acontecimentos, em diferentes épocas e regiões, marcam as lutas feministas e constituem a história dos direitos das mulheres (GARCIA, 2015, p. 11-15).

O termo feminismo foi primeiramente empregado por volta de 1911 nos Estados Unidos, quando escritores começaram a utilizá-lo no lugar das expressões do século XIX tais como "movimento das mulheres" e "problemas das mulheres", para descrever um novo movimento na história das lutas pelos direitos e liberdades das mulheres (GARCIA, 2015, p. 11). O feminismo pode ser entendido como um movimento que tem como ideal acabar com o sexismo, com a exploração sexista e com a opressão (HOOKS, 2019, p. 17).

De maneira ampla, o feminismo pode ser compreendido como um movimento político, visto que se contrapõe ao patriarcado e assim questiona as relações de poder, as opressões e as explorações de grupos de pessoas sobre outras. Nesse sentido, o feminismo propõe uma transformação social, econômica, política e ideológica de toda a sociedade, que pôde ser percebida, no decorrer do tempo, de formas variadas (TELES, 2017, p. 22).

Sendo assim, se desenvolveu ao longo da história como um movimento político, social e também filosófico, sendo que uma das suas principais características é a busca pela igualdade entre homens e mulheres e, consequentemente, por direitos iguais para todos. Esse é um movimento que reivindica a participação igualitária das mulheres na sociedade, a desconstrução da figura da mulher como um ser inferior aos homens e, assim, busca a superação da hierarquia de gênero (GARCIA, 2015, p. 11-15).

De acordo com o panorama internacional, o movimento feminista é divido em ondas estes são momentos em que há um acúmulo de reivindicações. Nesse sentido, no que diz respeito ao seu contexto histórico, ao estudar textos feministas é muito comum se deparar com menções ao "feminismo de segunda onda" ou à "terceira onda feminista". Essas denominações servem para indicar um momento histórico de relevante efervescência militante e/ou acadêmica em que determinadas pautas e questões feministas se insurgiram e dominaram o debate da época (SANTIAGO, 2020, p. 17).

A partir dessas ondas, a teoria feminista faz um recorte histórico sobre as principais reivindicações das mulheres, que se deram a partir do século XIX e abrangeram, sobretudo, a Europa e Estados Unidos. Entretanto, isso não quer dizer que não existiram reivindicações de mulheres antes desse período, nesses ou em outros lugares do mundo. Houveram outras 
reivindicações, no entanto, é o tempo e o pensamento que existem em um determinado local e em um determinado espaço de tempo que as define (GARCIA, 2015, p. 12-13).

Mais especificamente, no que diz respeito ao movimento feminista no Brasil, pode-se afirmar quanto à existência de três ondas. A primeira delas iniciou-se na metade do século XIX e teve como elemento central a luta sufragista. Desse modo, as suas reivindicações eram basicamente voltadas para as questões do direito ao voto para as mulheres brasileiras e à vida pública. Além disso, este foi um momento organizado pelas mulheres de classe média/alta (COSTA, 2005).

O direito de votar e de ser votado pode ser compreendido como uma das mais importantes batalhas das mulheres, na busca pela sua igualdade de gênero e pelo seu reconhecimento como sujeito de direitos. Esse foi o momento em que se iniciou o movimento feminista organizado - com as reivindicações sufragistas. As feministas compreendiam que o acesso a esse direito representaria o reconhecimento, pela sociedade e pelo Estado, de que elas possuíam as mesmas condições que os homens para gerir a vida coletiva e que elas tinham seus próprios interesses.

Nessa época, um dos nomes mais conhecidos da primeira onda feminista brasileira é o de Bertha Lutz, bióloga, cientista e ativista, ela foi uma das fundadoras da Federação Brasileira pelo Progresso Feminino (FBPF), organização que fez campanha pública pelo direito ao voto das mulheres brasileiras. Além disso, Bertha também criou a Liga pela Emancipação Intelectual da Mulher (LEIM), que foi produtiva e permitiu congregar esforços na luta pelo sufrágio feminino e para o avanço do debate público sobre os direitos das mulheres. Sendo assim, ela teve uma importante atuação na orientação de parlamentares na conquista do sufrágio feminino (PINTO, 2010, p. 15-23).

Desse modo, iniciada no final do século XIX, a primeira onda do feminismo no Brasil foi marcada por um conjunto de movimentações protagonizado por mulheres em torno da luta por igualdade política e jurídica entre os sexos. Em 1932 o direito ao voto feminino foi conquistado pelas mulheres brasileiras, tendo o então presidente Getúlio Vargas cedido aos apelos das mulheres e incorporado esse direito ao novo Código Eleitoral, nas mesmas condições que os homens e excluindo os analfabetos (ALVES, 2019, p. 49-63).

Já a segunda onda feminista teve seu início no começo da década de 1970 e ficou conhecida por alguns autores como o período da "Revolução Sexual". Nesse momento, além de lutarem pela valorização do trabalho da mulher, as feministas também reivindicavam pelo 
direito ao corpo e ao prazer (DUARTE, 2019, p. 25-45). Sendo assim, o movimento buscava denunciar a violação do corpo da mulher, reivindicando a autodeterminação quanto ao exercício da sua sexualidade, da procriação, da concepção, bem como o direito à informação e ao acesso aos métodos contraceptivos (ALVES; PITANGUY, 1991, p. 59-61).

No entanto, no contexto brasileiro, esse período foi um pouco diferente. Enquanto ao redor do mundo as mulheres se uniam para combater a discriminação sexual e lutar pela igualdade de direitos, no Brasil, o momento vivido impôs as mulheres que estas se posicionassem também contra a ditadura militar e a censura. Assim, durante o regime militar no país, que perdurou por 21 anos, o feminismo conquistou espaços enquanto movimento político. Nesse sentido, apesar dos obstáculos enfrentados, o movimento feminista brasileiro ganhou visibilidade e legitimidade na defesa e luta dos direitos das mulheres (PINTO, 2003, p. 41-55).

Articulando suas forças com outros grupos sociais que lutavam contra a repressão, as feministas questionavam as relações de poder e levaram a agenda dos direitos das mulheres para além dos espaços privados (PINTO, 2010, p. 15-23). Nesse cenário, no ano de 1975 houve a decisão histórica da ONU (Organização das Nações Unidas) de defini-lo como o Ano Internacional da Mulher. Diante disso, as questões relacionadas as mulheres ganhavam um novo status, mesmo diante de governos autoritários, como era o caso brasileiro (PINTO, 2003, p. 56-66).

Já na década de 1980, no Brasil, com o processo de redemocratização avançando, houve um momento de abertura política, sendo marcado, por exemplo, pela Campanha das Diretas-Já. Dessa campanha resultou a criação do CNDM - Conselho Nacional dos Direitos da Mulher, em 1985, que desempenharia papel bastante importante durante o período da Assembleia Constituinte, em 1987 e 1988. Esse Conselho teve como uma de suas funções articular as demandas dos movimentos feministas e das mulheres em geral (BIROLI, 2018, p. 180-182).

A participação das mulheres no processo constituinte foi de grande repercussão na história político-jurídica do país. Com o lema "Constituinte pra valer tem que ter palavra de mulher", o Conselho Nacional dos Direitos da Mulher, em 1985, criou e divulgou a campanha "Mulher e Constituinte", a qual mobilizou uma série de debates entre as mulheres, por todo o Brasil, e resultou na elaboração da "Carta das Mulheres Brasileiras aos 
Constituintes", importante documento feminista que foi entregue ao Congresso Nacional em 1986 (BIROLI, 2018, p. 180-182).

Sendo assim, o início dos anos 1980 representaram o período de abertura democrática na história do Brasil, sendo que as transformações que permearam o processo de redemocratização da sociedade brasileira estiveram centradas na garantia dos direitos sociais e individuais. O marco definitivo desse processo, além das eleições diretas para a presidência da República, que colocaram fim ao regime militar, foram os trabalhos da Assembleia Nacional Constituinte de 1987e 1988, que elaboraria um novo texto constitucional. ${ }^{1}$

\section{A Assembleia Nacional Constituinte de 1987 e 1988 e os direitos das mulheres: a atuação do Conselho Nacional dos Direitos da Mulher}

No plano político, com a reorganização dos partidos e graças à transição democrática que estava se fortalecendo devido às eleições para governadores, em novembro de 1982, o movimento feminista brasileiro passou a incorporar suas demandas nas campanhas eleitorais. Vários candidatos, homens e mulheres, passaram a incluir pautas relacionadas aos direitos das mulheres e às reivindicações feministas em suas propagandas. No Rio de Janeiro, foi elaborado um documento denominado de "Alerta Feminista", que foi amplamente divulgado e serviu de plataforma política para o movimento feminista (TABAK, 2002, p. 141-142).

As campanhas eleitorais ocorridas naquele momento foram muito diferentes das de períodos anteriores. Isso se deveu, entre outras coisas, pelo fato de que, naquele período, temas relacionados aos direitos das mulheres, que passaram a ser mais amplamente discutidos a partir de 1975, incorporaram as campanhas políticas. As temáticas abordadas pelos grupos feministas foram tratadas pelos candidatos da época na tentativa de conquistarem o eleitorado feminino (TABAK, 2002, p. 142).

Em 1985, em um cenário de mobilizações pelas Diretas-Já e pela redemocratização do país, o movimento feminista brasileiro passou a debater a respeito da criação de um órgão de âmbito federal que fosse capaz de elaborar e desenvolver nacionalmente leis e políticas

\footnotetext{
${ }^{1}$ Apenas para não deixar de mencionar todas as ondas do movimento feminista, após as conquistas das mulheres no texto constitucional, em 1988, e com entrada de uma nova década, passa a ser identificada uma terceira onda do movimento feminista. Este foi um momento em que as mulheres passaram a questionar o próprio movimento feminista, pois perceberam que os seus estudos e pesquisas abordavam experiências que representavam apenas as mulheres de classe média e brancas - não que anteriormente as mulheres não tenham feito esse questionamento, no entanto, foi com a terceira onda que isso veio à tona (BIROLI; MIGUEL, 2014).
} 
públicas. Desse modo, ele teria como objetivo elaborar uma agenda política que visasse a melhorar a condição da mulher, propondo novas leis, programas e aconselhamento para a presidência e para os ministérios no desenvolvimento de projetos específicos para a população feminina (PITANGUY, s.d, p. 1-3).

Durante a mobilização da campanha pelas Diretas-Já, que havia se iniciado desde 1983, e da instituição do Movimento de Mulheres pelas Diretas-Já, foi criado, em 1985, o Conselho Nacional dos Direitos da Mulher (CNDM). Esse Conselho nasceu da iniciativa de 40 mulheres do PMDB (Partido do Movimento Democrático Brasileiro), que procuraram Tancredo Neves, quando esse ainda era candidato, para obterem dele a garantia da instauração de um órgão estatal para cuidar dos direitos das mulheres. Com a sua morte, o vice-presidente José Sarney assumiu a presidência e manteve a promessa, tendo então criado o CNDM (PINTO, 2003, p. 71-72).

Sendo assim, em 1985 o governo federal criou esse Conselho, que se tornaria, em determinado momento, um importante instrumento de mobilização das mulheres por suas reivindicações. Ele contribuiu para que as feministas passassem a ocupar espaços institucionais e foi fundamental para as discussões que antecederam a Assembleia Constituinte (PINTO, 2010, p. 15-23). Ele se organizou através de comissões por áreas de trabalho como violência de gênero, saúde, educação, cultura, mulher negra, mulher rural, entre outras (OLIVEIRA, 2015, p. 187-190).

A sua criação, em agosto de 1985, durante o governo de José Sarney, se deu através da Lei 7.353, que o definia como sendo um órgão federal com autonomia administrativa e orçamento próprio e que respondia diretamente ao Presidente da República, a quem cabia a nomeação de sua presidenta. A sua formação atendeu à demanda de ativistas que consideravam importante, para a reconstrução das instituições políticas democráticas, que a agenda de igualdade de direitos entre homens e mulheres estivesse apta a ser implementada por um órgão federal dotado de autonomia (OLIVEIRA, 2015, p. 187-190). Sendo assim, o CNDM foi aprovado e criado a partir da Lei 7.353, de 29 de agosto de 1985,

(...) com a finalidade de promover, em âmbito nacional, políticas públicas que visem assegurar a eliminar a discriminação da mulher, assegurando-lhe condições de liberdade e de igualdade de direitos, bem como sua plena participação nas atividades políticas, econômicas e culturais do País. (BRASIL, Lei $\mathrm{N}^{\mathrm{o}}$ 7.353, 1985).

O Conselho Nacional era, na realidade, um órgão que possuía características de ministério e que tinha quadros técnicos, administrativos, orçamento próprio e autonomia 
financeira. Além disso, tinha também um centro de documentação e um Conselho Deliberativo, que tinha como combinado se reunir algumas vezes durante o ano (PITANGUY, 2018, p. 46). Fruto das articulações entre o movimento feminista, mulheres da sociedade civil e Tancredo Neves, o CNDM surgiu vinculado ao Ministério da Justiça. A criação desse espaço institucional pode ser considerada como uma grande vitória por parte das feministas para a ampliação das suas participações na política brasileira.

Nesse sentido, conforme a professora Flávia Biroli (BIROLI, 2018, p. 181):

Vinculado ao Ministério da Justiça, o CNDM respondia, no entanto, à Presidência
da República. Tinha como finalidade promover, em âmbito nacional, políticas para a
eliminação da discriminação contra a mulher, "assegurando-lhe condições de
liberdade e de igualdade de direitos". Entre suas competências estavam a formulação
de políticas para a "eliminação das discriminações que atingem a mulher", a
assessoria ao poder Executivo e a proposição de medidas "nas questões que atingem
a mulher", além da sugestão de projetos de lei à Presidência (...) (Lei 7.353 , de
1985), expondo linguagens e preocupações presentes nos feminismos brasileiros
naquele momento.

O Conselho Nacional dos Direitos da Mulher nasceu então vinculado à pasta da Justiça. A lei que o criou também prevê uma estrutura composta por uma Secretaria Executiva, uma Assessoria Técnica e por um Conselho Deliberativo. Esse Conselho Deliberativo foi designado pelo então Presidente da República, José Sarney, em 02 de setembro de 1985. Assim como o Conselho Deliberativo, o corpo técnico do CNDM era composto, na sua ampla maioria, por feministas vindas de diferentes regiões do Brasil (PIMENTA, 2010, p. 77).

O CNDM tinha como objetivo promover a criação de políticas públicas para as mulheres, sendo que uma das suas primeiras preocupações foi organizar um programa de trabalho que estivesse voltado para a Assembleia Nacional Constituinte, que teria seus parlamentares eleitos em 1986 e seria instaurada em 1987. Duas campanhas marcaram esse momento, "Constituinte para valer tem que ter direitos da mulher" e "Constituinte para valer tem que ter palavra de mulher" (OLIVEIRA, 2015, p. 189).

Esse foi um processo que envolveu articulações com diferentes grupos feministas e também com Conselhos Estaduais de Direitos das Mulheres, contando com a participação de organizações de mulheres empregadas domésticas, trabalhadoras rurais e aquelas pertencentes a centrais sindicais. Além disso, o CNDM também promoveu visitas às capitais dos Estados para que fossem apresentadas propostas para a nova Constituição (OLIVEIRA, 2015, p. 189). 
Nesse momento houve uma grande resposta positiva por parte da sociedade brasileira ao CNDM, e importantes passos foram ali tomados com a participação ativa da sociedade. Diante dessa repercussão, esse Conselho redigiu o documento denominado de Carta das Mulheres Brasileiras aos Constituintes, na qual foram apresentadas as propostas das mulheres para a criação de uma ordenação normativa que evidenciasse a igualdade entre todas as pessoas, independentemente do gênero, sendo que era dever do Estado a sua garantia e aplicabilidade (PITANGUY, 2019, p. 85-87). Esse documento foi entregue por Jacqueline Pitanguy, que era a atual presidenta do Conselho, ao Presidente da Assembleia Constituinte, Ulisses Guimarães, na abertura do novo processo constituinte (OLIVEIRA, 2015, p. 190).

Essa carta, promovida pelo CNDM mas de autoria de várias mulheres da sociedade civil brasileira, pode ser considerado como um dos documentos mais importantes elaborados pelo movimento feminista brasileiro. Ela foi dividida em vários capítulos, sendo que entre eles abordava questões referentes a família, trabalho, saúde, educação e cultura, violência e questões nacionais e internacionais (PITANGUY, 2019, p. 87-88). As mulheres que o elaboraram aproveitaram esse período para apresentarem aos constituintes as suas principais demandas.

O Conselho se mobilizou para atuar conjuntamente com os constituintes, sendo que as suas articulações foram fundamentais durante os trabalhos de preparação e, depois, durante o próprio período que foram realizados os trabalhos da Assembleia Nacional Constituinte. A presença das mulheres nesse período se deu de diversas formas. Fizeram parte dele grupos de mulheres não necessariamente vinculados ao movimento feminista, as próprias feministas, as deputadas eleitas e o Conselho Nacional dos Direitos da Mulher.

O Presidente José Sarney, no dia 28 de junho de 1985, encaminhou uma PEC (projeto de emenda constitucional) ao Congresso Nacional, com a proposta de convocação de uma Assembleia Nacional Constituinte. Sendo admitida a proposta, dela resultou a Emenda Constitucional n. ${ }^{\circ} 26$, de 27 de novembro de 1985. Assim, os parlamentares eleitos no pleito de 15 de novembro de 1986 - 487 Deputados Federais e 49 Senadores - e mais 23 dos 25 Senadores eleitos em 1982, num total de 559, deram início ao trabalho em $1^{\circ}$ de fevereiro de 1987, data da instalação da Assembleia Nacional Constituinte (PILATTI, 2019).

Esse foi um período de 20 meses de um trabalho que havia começado em 1987 e dado como encerrado em outubro de 1988, com a promulgação da nova Constituição Federal. Este pode ser considerado o marco inicial de uma luta pela igualdade entre homens e mulheres no 
Brasil, sendo que a sua mobilização foi bastante relevante - tanto nos períodos que antecederam a Constituinte como efetivamente durante os seus trabalhos - que foi facilitada pela criação de órgãos públicos específicos concernentes as questões das mulheres (TELES, 2017, p. 147-148).

Desse modo, é possível compreender que esse foi um momento paradigmático do tipo de participação, que até então era possível, do movimento feminista brasileiro na política. A formação da chamada "bancada feminina" no Congresso Constituinte pode exemplificar isso, tendo, na legislatura de 1986-1990, eleito 26 deputadas mulheres e nenhuma senadora. Esse era apenas um dos desafios que o movimento feminista precisaria enfrentar, a baixa representatividade política das mulheres. No entanto, embora possa parecer inexpressivo, 26 mulheres deputadas já era um número maior do que o usual para a época (PINTO, 1994, p. 207-215).

As discussões do novo texto constitucional na Assembleia Constituinte tiveram início em 24 Subcomissões Temáticas, agrupadas em 8 Comissões Temáticas. As subcomissões representaram um importante espaço de manifestação da sociedade civil, sendo o momento de ouvir as propostas populares para que os constituintes elaborassem as suas próprias propostas, além de debaterem e demonstrarem suas próprias convicções acerca dos temas tratados (PILATTI, 2019). Nessa época, as feministas tentaram articulações com as mulheres constituintes para poderem apresentar as suas reivindicações.

Sendo assim, as suas articulações com as deputadas mulheres durante esse período foram muito importantes, além de ser uma novidade no cenário político brasileiro. Essa foi a primeira vez, na história do país, em que houve a criação de um grupo suprapartidário de deputadas constituintes que se articularam e ofereceram apoio a causa das mulheres. As suas atuações no congresso ficaram conhecidas como "lobby do batom" (PITANGUY, s.d, p. 13). Esse era o momento que o movimento feminista tinha para imprimir a sua marca no novo texto constitucional que viria a ser promulgado.

\section{A conquista do Princípio da Igualdade na Constituição Federal de 1988}

\footnotetext{
${ }^{2}$ Essa denominação, "Lobby do Batom”, foi uma classificação feita pelos próprios constituintes da ANC que, de maneira irônica, tinham a intenção de minimizar, de debochar, das contribuições das mulheres no processo constituinte. Assim, pode ser entendida como uma marca machista que tentou desqualificar a importância deste momento na história política em relação à atuação das mulheres, reduzindo-as a indivíduos que só sabem conversar sobre maquiagem e "futilidades", "coisas de mulher".
} 
De início cumpre conceituar o que são princípios. Esses podem ser compreendidos como fontes do direito com caráter fundamental, normalmente mais difusos, vagos e indeterminados que as regras. Sendo assim, são normas com papel essencial no ordenamento e são funções desempenhas por eles dentro do ordenamento jurídico ser interpretativo e fundamentador das demais normas (CANOTILHO, 2000). Além disso, eles não são iguais as normas, pois desempenham funções diferentes e complementares (ÁVILA, 2015).

Dessa forma, os princípios podem ser definidos como juízos fundamentais e servem como alicerce ou como garantia de certeza a um conjunto de juízos. Sendo assim, são fundamentadores de um sistema de conhecimento, tendo como sua característica principal suas generalidades e abrangência (ÁVILA, 2015). No campo do direito e também em outros seguimentos, os princípios são tidos como fundamento, como instrumentos norteadores e que servem para dar sentido a alguma interpretação ou decisão.

Quanto aos princípios constitucionais e o seu papel na democracia brasileira, na antiguidade esses possuíam apenas o papel de preencher lacunas, mas já não é mais apenas assim. Esses se tornaram parâmetros de aferição de constitucionalidade do sistema jurídico brasileiro e se colocam como normas essenciais no que tange as estruturas basilares de um sistema que constitui um necessário fundamento de modo a proporcionar uma interpretação e sistemática aplicação do direito positivo (ESPÍNDOLA, 2013). De outro modo, "princípios são, pois verdades ou juízos fundamentais, que servem de alicerce ou de garantia de certeza a um conjunto de juízos, ordenados em um sistema de conceitos relativos à dada porção da realidade" (REALE, 2002).

No que diz respeito especificamente ao Princípio da Igualdade, esse é consagrado nas Constituições Brasileiras desde o início do período republicano como um princípio de igualdade perante a lei, que deve tratar todos igualmente. Nesse sentido, a prescrição contida no caput do artigo $5^{\circ}$ da Constituição Federal de 1988 mantém a tradição constitucional quanto ao tratamento isonômico de todas as pessoas. Esse dispositivo prevê que todos são iguais perante a lei, sem distinção de qualquer natureza, sendo garantido aos brasileiros e aos estrangeiros residentes no país a inviolabilidade do direito à vida, à liberdade, à igualdade, à segurança e à propriedade (BRASIL, CONSTITUIÇÃO FEDERAL DE 1988).

A primeira Constituição Republicana, datada de 1891, apesar de conter princípios de influência iluminista advindos da Revolução Francesa, não se preocupou com os direitos das mulheres (CASTRO, 1983). Aquele texto constitucional não tratou de forma expressa o 
Princípio da Igualdade, sendo que no seu artigo $72, \S 2^{\circ}$, ao trabalhar com esse tema, trouxe como previsão que todos são iguais perante a lei e que "a República não admite privilégios de nascimento, desconhece foros de nobreza e extingue as ordens honoríficas existentes e todas as suas prerrogativas e regalias, bem como os títulos nobiliárquicos e de conselho" (BRASIL, CONSTITUIÇÃO DA REPÚBLICA DOS ESTADOS UNIDOS DO BRASIL, 1891).

Desse modo, pode-se compreender que nas constituições anteriores a de 1988 a previsão de um tratamento isonômico entre as pessoas já havia sido inserido, no entanto, ainda não havia uma preocupação em ressaltar explicitamente acerca da proibição de tratamento distinto entre os sexos. A igualdade prevista por esses textos era aquela equivalente a um tratamento perante a lei, mas nenhum deles ressaltava especificamente acerca dos direitos das mulheres (CASTRO, 1983).

Foi a constituição de 1934 que trouxe, em seu artigo $113 \S 1^{\circ}$, que "todos são iguais perante a lei. Não haverá privilégios, nem distinções, por motivo de nascimento, sexo, raça, profissões próprias ou do país, classe social, riqueza, crenças religiosas ou ideias políticas" (BRASIL, CONSTITUIÇÃO DA REPÚBLICA DOS ESTADOS UNIDOS DO BRASIL, 1934). Essa foi a primeira vez que uma constituição brasileira trouxe, em específico, a igualdade, tendo assim repudiado, pelo menos formalmente, a discriminação entre homens e mulheres (CASTRO, 1983).

A igualdade pode ser compreendida como uma reivindicação "óbvia" por parte de qualquer movimento que represente grupos oprimidos. As feministas, desde as suas primeiras manifestações, também apresentaram essa como uma de suas demandas fundamentais, reivindicando liberdades iguais aos homens (BIROLI; MIGUEL, 2014, p. 63). Com o decorrer da história e ao longo do tempo elas propuseram reivindicações para a construção de uma igualdade entre homens e mulheres.

Nesse sentido, para a redação da Constituição Federal de 1988, elas trabalharam em conjunto com o Conselho Nacional dos Direitos da Mulher. Elas conquistaram a aprovação da Carta das Mulheres Brasileiras aos Constituintes, documento no qual elas apresentavam as principais demandas das mulheres brasileiras para a elaboração de uma ordenação normativa que evidenciasse a igualdade entre todas as pessoas, independentemente do gênero (PITANGUY, s.d, p. 1-3). Dividida em princípios gerais e reivindicações específicas, a Carta apresenta pontos centrais que não poderiam ficar fora do novo texto constitucional e destacava que, para a efetivação do princípio da igualdade, seria fundamental que a futura 
Constituição Brasileira estabelecesse preceitos legais que visem eliminar todas as formas de discriminação.

Desse modo, em 1985, com as campanhas por uma nova Constituinte livre e soberana, os movimentos feministas desenvolveram intensas campanhas para mobilizar a população acerca das questões específicas das mulheres. Isso sem deixar de lado as lutas mais amplas da sociedade, aquelas relacionadas a salários, desemprego, custo de vida, reforma agrária e dívida externa. Desde o final da década anterior, em 1978, com a campanha eleitoral, as feministas já estavam organizadas e exigiam dos candidatos que as suas reivindicações no tocante à legislação de proteção à mulher fossem por eles consideradas (GOLDENBERG; TOSCANO, 1992, p. 43-44).

A Constituição Federal de 1988 trouxe então no seu artigo $5^{\circ}$ que "todos são iguais perante a lei, sem distinção de qualquer natureza, garantindo-se aos brasileiros e aos estrangeiros residentes no País a inviolabilidade do direito à vida, à liberdade, à igualdade, à segurança e à propriedade, nos termos seguintes: I - homens e mulheres são iguais em direitos e obrigações, nos termos desta Constituição". Esse dispositivo, assim como o contido no $\S 5^{\circ}$ do art. 226 (“os direitos e deveres referentes à sociedade conjugal são exercidos igualmente pelo homem e pela mulher") (BRASIL, CONSTITUIÇÃO FEDERAL DE 1988), não deixam dúvidas quanto à importância que a Constituição confere ao princípio da igualdade, tão ampla quanto possível, entre homens e mulheres.

Além de inaugurar o capítulo dos direitos individuais com o princípio de que todos são iguais perante a lei, sem distinção de qualquer natureza, a Constituição reafirma esse princípio por meio de muitas normas, algumas diretamente determinadoras da igualdade, outras buscando a equidade entre os desiguais mediante a concessão de direitos sociais fundamentais. Desse modo, a previsão do Princípio da igualdade na Constituição Federal de 1988 foi um grande passo para os direitos das mulheres e o movimento feminista, sendo que esse princípio gera consequências positivas até os dias atuais. Ele prevê a igualdade de aptidões e de possibilidades entre todos os cidadãos de gozar de tratamento isonômico pela lei.

\section{Considerações finais}

O presente artigo buscou analisar a influência dos movimentos feministas na conquista do Princípio da Igualdade em 1988 e a participação das mulheres na constituinte. Conforme 
foi apresentado, pode-se entender que as lutas das mulheres e dos movimentos feministas no contexto brasileiro influenciaram na conquista dos direitos das mulheres e também na edição do Princípio da Igualdade previsto na Constituição Federal brasileira de 1988.

No que se refere aos Direitos Humanos das mulheres no Brasil, a Constituição de 1988 desempenha uma referência primordial, pois resultou em uma verdadeira mudança de paradigma do Direito brasileiro no que se refere à igualdade de gênero, conforme relatado. Ressalta-se ainda, a articulação das mulheres brasileiras, no que pese aos Direitos Humanos, na elaboração de documentos e demandas para as conferências e tratados internacionais, avançando largamente na conquista dos direitos das mulheres.

Nesse sentido, ao longo da pesquisa foram apresentados um breve contexto histórico do movimento feminista, não apenas no Brasil, mas ao redor do mundo, retratando as suas principais reivindicações, sendo possível concluir-se que o movimento feminista foi um importante movimento social na luta e conquista dos direitos das mulheres brasileiras. As mulheres e os movimentos sociais feministas marcaram a nova Constituição, estando muitas de suas reivindicações incorporadas ao texto constitucional. A promulgação da Constituição Federal, em 1988, foi considerada um importante instrumento para a redemocratização do Brasil e também um importante instrumento na luta dos direitos feministas.

O tema que foi abordado neste artigo é de grande importância e significado, e sendo assim, para um melhor entendimento, foi necessário, primeiramente, abordar sobre a história do feminismo e dos movimentos feministas, para depois abordar de que forma os movimentos feministas influenciaram na conquista dos direitos das mulheres e sobre esses direitos na Constituição de 1988, para, por fim, abordar sobre a criação do Princípio da Igualdade presente na Constituição e a influência dos movimentos feministas nesse processo.

Assim, a promulgação da Constituição Federal, em 1988, representou o marco político-jurídico da transição democrática e da institucionalização dos direitos humanos no país. A Carta Magna de 1988, por sua vez, trouxe ainda várias mudanças paradigmáticas com a presença dos direitos e garantias fundamentais, os direitos individuais e os sociais, que garantem a dignidade da pessoa humana.

Sendo assim, diante do exposto, é possível compreender que, de fato, a Constituição de 1988 foi um marco na democracia do Brasil, prevendo em seu texto os direitos fundamentais e princípios importantes para a preservação da dignidade humana, um grande avanço para Estado Democrático de Direito. Assim, é notória a participação e a influência que 
os movimentos feministas tiveram no que diz respeito à criação do princípio da igualdade presente no texto constitucional, tendo em vista seu aspecto histórico.

A conquista do Princípio da Igualdade gera consequências positivas até os dias de hoje, sendo que a luta feminista continua. Assim, pode-se concluir que os movimentos feministas tiveram grandes influências na conquista dos direitos das mulheres e na incorporação do Princípio da Igualdade no texto de 1988. A fim de alcançar a igualdade nas relações sociais, a mulher percorreu um longo caminho até os dias atuais, no sentido de conquistar direitos igualitários, uma vez que se configura na história a cultura da repressão e patriarcado. Dessa forma, percebe-se que o movimento feminista agregou muitas vitórias e conquistas para a emancipação da mulher, porém é incontestável que ainda há muitos desafios atualmente no que se refere à busca de uma sociedade mais igualitária e justa para as mulheres.

\section{Referências}

ALVES, Branca Moreira. A luta das sufragistas. In: HOLLANDA, Heloísa Buarque de (Org.). Pensamento feminista brasileiro: formação e contexto. Rio de Janeiro: Bazar do Tempo, 2019.

ALVES, Branca Moreira; PITANGUY, Jacqueline. O que é feminismo. São Paulo: Editora Brasiliense, 1991.

ÁVILA, Humberto. Teoria dos Princípios - 16ª ed. - São Paulo: Malheiros, 2015.

BIROLI, Flávia. Gênero e desigualdades: limites da democracia no Brasil. São Paulo: Boitempo, 2018.

BIROLI, Flávia. MIGUEL, Luis Felipe. Feminismo e política. São Paulo: Boitempo, 2014.

BRASIL. Constituição da República dos Estados Unidos do Brasil. Rio de Janeiro: Congresso Nacional Constituinte, 1891. Disponível em:

http://www.planalto.gov.br/ccivil 03/Constituicao/Constituicao91.htm. Acesso em: 4 abr. 2020.

BRASIL. Constituição da República Federativa do Brasil: Texto constitucional promulgado em 5 de outubro de 1988. Brasília: Senado Federal, 1988.

BRASIL. Lei $\mathbf{N}^{\mathbf{0}}$ 7.353. De 29 de agosto de 1985. Cria o Conselho Nacional dos Direitos da Mulher - CNDM e dá outras providências. Disponível em http://www.planalto.gov.br/ccivil_03/leis/1980-1988/L7353.htm. Acesso em 10 abr. 2021. 
CANOTILHO, J. J. Gomes. Direito Constitucional e teoria da Constituição. $4^{\mathrm{a}}$ ed. Coimbra: Almedina, 2000.

CANOTILHO, J.J. Gomes; MENDES, Gilmar Ferreira; SARLET, Ingo Wolfgang; STRECK, Lenio Luiz. Comentários à Constituição do Brasil. São Paulo: Saraiva/Almedina, 2013.

CASTRO, Carlos Roberto Siqueira. O princípio da isonomia e a iguadade da mulher no Direito Constitucional. Rio de Janeiro: Forense, 1983.

COSTA, Ana Alice Alcantara. O movimento feminista no Brasil: dinâmicas de uma intervenção política. Revista Gênero, Niterói, v. 5, n. 2, p. 9-35, 1 sem. 2005.

DUARTE, Constância Lima. Feminismo: uma história a ser contada. In: HOLLANDA, Heloisa Buarque de (Org.). Pensamento feminista brasileiro: formação e contexto. Rio de Janeiro: Bazar do Tempo, 2019.

ESPÍNDOLA, Ruy Samuel. A constituição de 1988 como garantia da democracia brasileira- o papel dos princípios constitucionais (aportes comemorativos de seus 25 anos); Revista Brasileira de Direito Eleitoral - RBDE. Belo Horizonte; ano 5. nº 9, 2013.

GARCIA, Carla Cristina. Breve história do feminismo. São Paulo: Claridade, 2015.

GOLDENBERG, Miriam. TOSCANO, Mirian. A revolução das mulheres: um balanço do feminismo no Brasil. Rio de Janeiro: Revan, 1992.

HOOKS, Bell. O feminismo é para todo mundo: políticas arrebatadoras. Trad. Ana Luiza Libânio. - $3^{\mathrm{a}}$ edição. Rio de Janeiro: Rosa dos Tempos, 2019.

OLIVEIRA, Adriana Vidal de. Constituição e Direitos das Mulheres: Uma análise dos estereótipos de gênero na Assembleia Constituinte e suas consequências no texto constitucional. Curitiba: Juruá, 2015.

PILATTI, Adriano. A Constituinte de 1987-1988: Progressistas, Conservadores, Ordem Econômica e regras do Jogo. $3^{a}$ Ed. Rio de Janeiro: Lumen Juris, 2019.

PIMENTA, Fabrícia Faleiros. Políticas feministas e os feminismos na política: O Conselho Nacional dos Direitos da Mulher (1985-2005). 2010. 312f. Tese (Doutorado em História) Universidade de Brasília, Brasília, 2010.

PINTANGUY, Jacqueline. As mulheres e a Constituição de 1988. Disponível em http://cepia.org.br/wp-content/uploads/2017/11/nov089.pdf. Acesso em 07 abr. 2021.

PINTO, Céli Regina Jardim. Feminismo, História e Poder. Rev. Sociol. Polít., Curitiba, V. 18, N. 36, P. 15-23, Jun. 2010.

PINTO, Céli Regina Jardim. Participação (Representação?) Política da Mulher no Brasil: Limites e Perspectivas. In: SAFFIOTI, Heleieth; MUÑOZ-VARGAS, Monica (Orgs.). 
Mulher brasileira é assim. Rio de Janeiro: Rosa dos Tempos: NIPAS; Brasília: Unicef, 1994.

PINTO, Céli Regina Jardim. Uma história do feminismo no Brasil. São Paulo: Editora Fundação Perseu Abramo, 2003.

PITANGUY, Jacqueline. A carta das mulheres brasileiras aos constituintes: memórias para o futuro. In: HOLLANDA, Heloisa Buarque de (Org.). Pensamento feminista brasileiro: formação e contexto. Rio de Janeiro: Bazar do Tempo, 2019.

PITANGUY, Jacqueline. Celebrando os 30 Anos da Carta das Mulheres Brasileiras aos Constituintes. In: SEMINÁRIOS 30 ANOS DA CARTA DAS MULHERES AOS

CONSTITUINTES, 2018, Rio de Janeiro. Série Anais de Seminários 30 anos da Carta das Mulheres aos Constituintes. Rio de Janeiro: EMERJ, 2018.

REALE, Miguel. Lições preliminares de direito. $27^{\text {a }}$ Ed. Editora Saraiva. 2002.

SANTIAGO, Bruna. O que são as ondas do feminismo? Entenda um pouco da história do feminismo, e como chegamos até aqui. Rev. Digital QG Feminista, No 11, Fev. 2020.

TABAK, Fanny. Mulheres públicas: participação política e poder. Rio de Janeiro: Letra Capital, 2002.

TELES, Maria Amélia de Almeida. Breve história do feminismo no Brasil e outros ensaios. São Paulo: Editora Alameda, 2017. 